\title{
Improving the efficiency of maintenance of heavy-duty engines
}

\author{
Nikolay Zagorodniy ${ }^{1 *}$, Alexander Novikov ${ }^{2}$, and Ivan Novikov ${ }^{1}$ \\ ${ }^{1}$ Belgorod state technological University named V.G. Shukhov, 308012, Belgorod, st. Kostyukova 46, \\ Russia \\ ${ }^{2}$ Orel State University named I.S. Turgenev, 302026, Orel, st. Komsomolskaya 9, Russia
}

\begin{abstract}
The paper deals with the issue of improving the efficiency of heavy-duty engines by restoring worn parts. The influence of the reserve of spare parts on the reliability of the engines is determined. It is proposed to carry out maintenance on centralized bases that serve several auto enterprises. Established: the method of replacing worn elements will reduce the number of engine overhauls.
\end{abstract}

\section{Introduction}

It has already been noted that the recent changes in the design principles of production facilities, which are based on the use of replaceable structural elements, in order to improve their maintainability, in fact, do not reflect the achieved level of maintainability of production facilities. And the reason for this is the immutability of organizational forms up to the present time.

The concentration of disassembly and assembly work performed at specialized repair enterprises cannot be subordinated, from an economic point of view, to the requirements of the necessary concentration of work on the restoration of elements [1].

The complexity of assembly, with the existing methods of organization and technology of maintenance of automobile engines, with programs exceeding 2.0 thousand per year, is practically not reduced (Figure 1), and with programs much larger, with the restoration of elements, there is a noticeable decrease in labor costs [4].

If we take into account that the restoration of the performance of automobile engines can be carried out, in most cases, without their complete disassembly (replacement of the sleeve-piston group, block head, etc.), then the possibility and necessity of separate organization of work on the replacement of worn-out elements and components and their restoration becomes obvious [2].

\footnotetext{
*Corresponding author: zagor76@mail.ru
} 


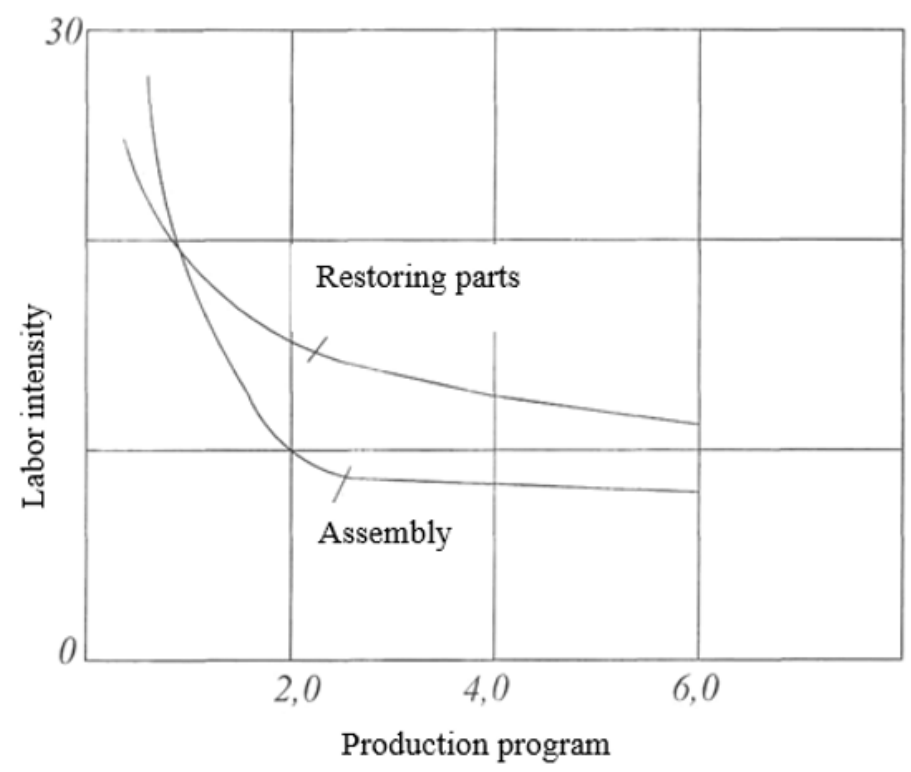

Fig. 1. The nature of the change in labor intensity during engine repair YAMZ-240N

\section{Theoretical research}

Centralized restoration of worn-out components and components should be organized at the level of large-scale or mass production, and their replacement, when restoring the performance of automobile engines, at enterprises with a significantly lower concentration of work [3,5]. Such maintenance can be performed at centralized maintenance bases that would serve several motor transport companies, and would have simple equipment for disassembly and assembly and related work.

The separate organization of work on the replacement of worn-out elements and their restoration further confirms the expediency of this direction, since disassembly and assembly work during maintenance is auxiliary, necessary for the control, sorting and subsequent restoration of elements. These works also do not require complex technological equipment.

Restoration of elements is the main type of work for specialized repair industries. Therefore, more complex and expensive equipment will be required to perform them.

The planned frequency of replacement of individual elements and components is a condition for redundancy, as the basis for maintaining the reliability of production facilities at a given level.

Redundancy in road transport consists in the presence of redundancy of a certain part of spare parts, including elements "in bulk", assemblies and assemblies.

\section{Evaluation of engine reliability}

Consider the effect of creating a reserve on the reliability of automobile engines [15].

Suppose that the duration of replacement of a faulty unit (element) is negligible, in comparison with the duration of the engine's failure-free operation, then it can be neglected [17]. The possibility of such an assumption is confirmed by the fact that the downtime for replacing the main components of the YaMZ-240N engine does not exceed 2\% of its working time. When performing a replacement during the inter-shift (non-working) time, 
the duration of restoring the engine's operability is equal to zero, since maintenance, in this case, is performed during natural breaks in operation [6,9].

At the same time, we can assume that the restoration of the car engine performance occurs instantly. Therefore, in this case, all the main provisions of the theory of redundancy of technical devices are applicable [8].

According to the theory of reliability of complex mechanical systems, redundancy can be general and piecemeal.

If the engine is reserved as a whole, this will be called general redundancy, and when individual elements (components and parts) are reserved, it will be called piecemeal $[18,20]$.

Both general and element-by-element redundancy, according to the method of including the reserve, can be with a permanent reserve and replacement (cold reserve) [19].

A permanent reserve that works simultaneously with the main one is of little use for automobile engines. The replacement reserve, until the failure of the main element, is in working condition and stored in the warehouse. Such a reserve, before it is included in the work, must be operational $[13,16]$.

The advantage of a reserve with replacement is that the main element of any engine can be replaced by a reserve (sliding redundancy) [7]. This will contribute to a significant reduction in the number of redundant elements at the same time a given level of reliability (redundancy with fractional multiplicity) [21].

The engine, first of all, is a technical system consisting of many elements (assembly units, elements). A malfunction of one of the elements may cause the entire system to fail. If the failure of each element is represented as a random event, then according to the rule of multiplication of probabilities, the reliability of the car engine can be represented as follows:

$$
P_{\partial}^{0}=P_{1}(l) P_{2}(l) P_{3}(l) \ldots P_{i}(l) \ldots P_{n}(l)=\Pi P_{i}(l)
$$

where $P_{\partial}{ }^{0}$ is the reliability of the automobile engine; $P_{1}(\mathrm{l}) P_{2}(l) P_{3}(l) \ldots P_{i}(l)$ - is the reliability of the individual elements (parts, assemblies) of the engine.

The probability of proper operation of the element (node) $P_{i}(l)$ and the probability of failure $q_{i}(l)$ in a given time interval (mileage interval) are related by the following relation:

$$
P_{i}(l)+q_{i}(l)=1 \quad q_{i}(l)=1-P_{i}(l) .
$$

If we assume that some node, having reached the limit state (for example, by wear), will be replaced by a backup, then the probability of failure of the $i$-th node, taking into account the input of the backup, will have the form:

$$
Q_{i}(l)=q_{i}(l) \cdot q_{i}(l)=\left[1-P_{i}(l)\right]^{2},
$$

then the reliability of this node will be:

$$
P_{i}(l)=1-Q_{i}(l)=1-q_{i}^{2}(l)=1-\left[1-P_{i}(l)\right]^{2},
$$

If there are $m-1$ backup nodes of the same name, the reliability of the node will be as follows:

$$
P_{i}(l)=1-Q_{i}(l)=1-q_{i}^{m}(l)=1-\left[1-P_{i}(l)\right]^{m},
$$


The reliability of the engine, consisting of «n» nodes, each of which is reserved in the number of «m $m_{i}-1 »$ pieces, is determined as follows:

$$
\mathrm{P}_{g}^{\prime}(l)=\prod_{i=1}^{n} \cdot \mathrm{P} i(l)=\prod_{i=1}^{n}\left\{1-\left[1-P_{i}(l)\right]^{m_{i}}\right\},
$$

We will analyze the change in the probability of failure-free operation of the YaMZ$240 \mathrm{~N}$ engine, depending on the backup method. We will use the data on the reliability of the components and elements of this engine, given in Table 1.

The probability of failure-free operation of a non-redundant engine, in this interval, is determined by the formula 1 . Substituting the corresponding values, we get:

$$
P_{g}^{0}(l)=\prod_{i=1}^{n} \operatorname{Pi}(l)=0,092 \cdot 0,57 \cdot 0,82^{2} \cdot 0,835=0,029 .
$$

Taking the values of the reliability of the components and elements, it is revealed that only $2.9 \%$ of the engines will work out a failure-free run of 80-100 thousand $\mathrm{km}$.

Table 1. Data on the reliability of the main parts of the YaMZ-240N engine in the specified mileage interval

\begin{tabular}{|c|l|c|}
\hline № & \multicolumn{1}{|c|}{$\begin{array}{c}\text { Name of the main elements and components that are } \\
\text { included in the spare parts }\end{array}$} & $\begin{array}{c}\text { The probability of failure-free } \\
\text { operation in the range of 80-100 } \\
\text { thousand km }\end{array}$ \\
\hline 1 & \multicolumn{1}{|c|}{2} & 3 \\
\hline 1 & Cylinder-piston group: & 0,092 \\
& - cylinder liner & 0,45 \\
& - piston & 0,455 \\
2 & - piston rings & 0,45 \\
3 & Connecting rod inserts & 0,57 \\
4 & Cylinder head & 0,82 \\
5 & Block head gasket & 0,82 \\
\hline
\end{tabular}

If there is a set of all spare parts, the reliability of the engine is determined by the formula 4. Substituting the corresponding values, we get:

$$
\begin{gathered}
\mathrm{P}_{g}^{\prime}(l)=\prod_{i=1}^{n}\left\{1-\left[1-P_{i}(l)\right]^{2}\right\}=\left[1-(1-0,092)^{2}\right] \cdot\left[1-(1-0,57)^{2}\right] . \\
{\left[1-(1-0,82)^{2}\right]^{2} \cdot\left[1-(1-0,835)^{2}\right]=0,13}
\end{gathered}
$$

In this case, the reliability of the engine, in comparison with engines that do not have a spare reserve, will increase in:

$$
\frac{0,13}{0,029}=4,48
$$

If there is an engine assembly in stock, instead of individual components and elements, then the reliability of the engine, taking into account the backup, will be:

$$
P_{g}(l)=1-\left[1-P_{g}{ }^{0}(l)\right]^{2}=1-(1-0,029)^{2}=0,057 .
$$


In this case, the reliability of the engine, when reserving individual components and elements, is 1.97 times higher than with the general redundancy:

$$
\frac{0,057}{0,029}=1,97
$$

\section{Conclusion}

The reliability of the engine $\mathrm{P}_{g}(l)=0,13$ can be ensured with a general backup, but then a significant number of spare engines will be required. And this, in turn, will lead to an increase in the value of the reserve (stock).

Therefore, in order to maintain the necessary level of reliability of automobile engines and reduce the cost of spare parts, it is economically feasible to create a reserve fund not from the assembled engines, but from its components and elements.

According to the theory of reliability, the gain obtained by reserving increases with any splitting of the reserve [10].

The most profitable, from this point of view, should be considered the reservation of individual elements. This, in fact, is currently the case in the practice of road transport.

Meeting the requirements for assembly quality, minimizing costs, and ease of performing work on replacing worn-out elements, caused the engine assembly units to be used as a spare (backup) element. Hence, we can draw a very important conclusion about the need to organize centralized restoration of worn-out components, rather than individual elements implemented in bulk [12, 14].

In solving the problem of restoring the performance of automobile engines, this is a completely new approach, first proposed in the USSR in the second half of the 20th century [11].

The considered material allows us to conclude that at the present stage, there are objective prerequisites for the organization of maintenance of automobile engines and other objects of production of long-term use, which is based on the method of replacing worn-out elements. This will lead to a reduction in the number of expensive capital technical services performed.

\section{References}

1. Abroskin A.S. Application of modern automation systems in open pit mining / A.S. Abroskin // Bulletin of the Tomsk Polytechnic University. Engineering of georesources. - 2015. - T. 326. No. 12. - S. 112-130;

2. Agafonov D.V. Technological transport of Lebedinsky GOK / D.V. Agafonov, A.S. Yakushev, V.S. Lyashchev // Mining Journal. - 2017. - No. 5. - S. 38-41;

3. Belyaev, A., Gordienko, V., Druzhinin, P., Evtukov, S. (2020). Mathematical model for selecting the best technology for restoring road construction machines. E3S Web of Conferences,164. 10.1051/e3sconf/202016403044;

4. Blam Yu.Sh., Mashkina L.V. Models and methods of applied analysis (production systems): textbook. - method. complex for the course [Electronic resource] / NSU. Novosibirsk, 2008. - 2 Access mode [25.04.18]: http://econom.nsc.ru/efnsu/Mimpa2.htm;

5. Chernyaev, I., Oleshchenko, E., Danilov, I. (2020). Methods for continuous monitoring of compliance of vehicles' technical condition with safety requirements during operation. Transportation Research Procedia, 50, 77-85. 10.1016/j.trpro.2020.10.010; 
6. Dekhterinsky L.V. Some theoretical questions of the technology of car repair. / L.V. Dekhterinsky. - M .: "High school", 1970.

7. Evtiukov, S. A., Evtiukov, S. S., Kurakina, E. V. (2020). Smart transport in road transport infrastructure. Paper presented at the IOP Conference Series: Materials Science and Engineering, 832(1) doi:10.1088/1757-899X/832/1/012094;

8. Gavrishev S.E. Organizational and technological methods for increasing the reliability and efficiency of open pit mines: monograph. - Magnitogorsk: MSTU, 2002 .-- 231 p.;

9. Kozhukhovskaya, L., Baskov, V., \& Ignatov, A. (2017). Modular management of indicators of efficiency and safety of transportation processes. Transportation Research Procedia, 20 361-366. doi:10.1016/j.trpro.2017.01.048;

10. Krivshin A. P. Repair of bulldozers by aggregate method. / A. P. Krivshin, N. F. Pechenin. - M.: "Transport", 1964.

11. Krupenya V.M. Organization of scheduled preventive maintenance. / V.M. Krupenya et al. - M .: "Mining Journal", 1984, No. 10. P. 9 - 10;

12. Lepetyukha S. V., Yakushev A. S. State and prospects of development of technological motortransport at Lebedinsky GOK. Gornyi Zhurnal. 2007. No. 7. pp. 25-27;

13. Nesterenko A.V. Repair service of the plant / A.V. Nesterenko, S.A. Razgulov, E.Yu. Berestnev, A.A. Nikulin // Mining Journal. - 2017. - No. 5. - S. 42-45;

14. Paley L.M. Managerial and engineering support of open pit mine production phase I at v. grib mining and progressing combine || Eurasian mining. - 2014. № 2. - P. 20-22;

15. Report of Stoylensky GOKA on implementation of the plan on prime cost of products. - StaryOskol: SGOK, 2007-2011. - 52 pages.

16. Semykina A. S. Features of the use of cars in low temperature conditions / A. S. Semykina, N. A. Kurinyi / / Modern automotive materials and technologies (SAMIT2016): collection of articles of the VIII International Scientific and Technical Conference / ed.: E. V. Ageev (ed.) [et al.]; Yugo-Zapad State University. Kursk, 2016. pp. 223-226.

17. Semykina A.S. Analysis of the types of iron ore raw materials and the process of their transportation / Semykina, N.A. Zagorodny, Yu.V. Fomenko, A.A. Konev // Scientific and technical aspects of the innovative development of the transport complex: a collection of scientific papers based on the materials of the III International Scientific and Practical Conference on May 25, 2017 / Ministry of Education and Science of the DPR, etc. - Donetsk: DAT, 2017, pp. 27-31;

18. Semykina A.S. Identification of problems of the transport complex of mining and processing enterprises / Semykina A.S., Zagorodny N.A. // New materials, equipment and technologies in industry: materials of the international. scientific and technical conf. young. scientists / Ministry of Education Resp. Belarus, Ministry of Education and Science Ros. Federation, Belarus. - Grew. un-t; editorial board: I. S. Sazonov (chief editor) [and others]. - Mogilev: Belarusian. - Grew. un-t, 2017;

19. Simulating multilane traffic flows based on cellular automata theory [Electronic resource]/ M. A. Trapeznikova, I. R. Furmanov, N. G. Churbanova, R. Lipp / Mathematical Models and Computer Simulations, 2012. - 53 - 61 p;

20. Taha, Hemdi A. Introduction to Operations Research, 7th Edition [Text]: Per. from English - M .: Publishing house "Williams", 2005. - 912 p .: ill .;

21. Tarikov D.Sh. Analysis of the production activity of the mining enterprise and the development of methods for optimizing the transport and cargo complex / D.Sh. 
Tarikov, S.N. Kornilov // Actual problems of modern science, technology and education - Magnitogorsk: Publishing house of Magnitogorsk. state tech. un-ta them. G.I. Nosova, 2012. - T. 1. - P.96-99. 